Molecular surface structure of tetracene mapped by the atomic force microscope

R. M. Overney, L. Howald, J. Frommer, E. Meyer, and H.-J. Güntherodt

Citation: The Journal of Chemical Physics 94, 8441 (1991); doi: 10.1063/1.460077

View online: http://dx.doi.org/10.1063/1.460077

View Table of Contents: http://aip.scitation.org/toc/jcp/94/12

Published by the American Institute of Physics

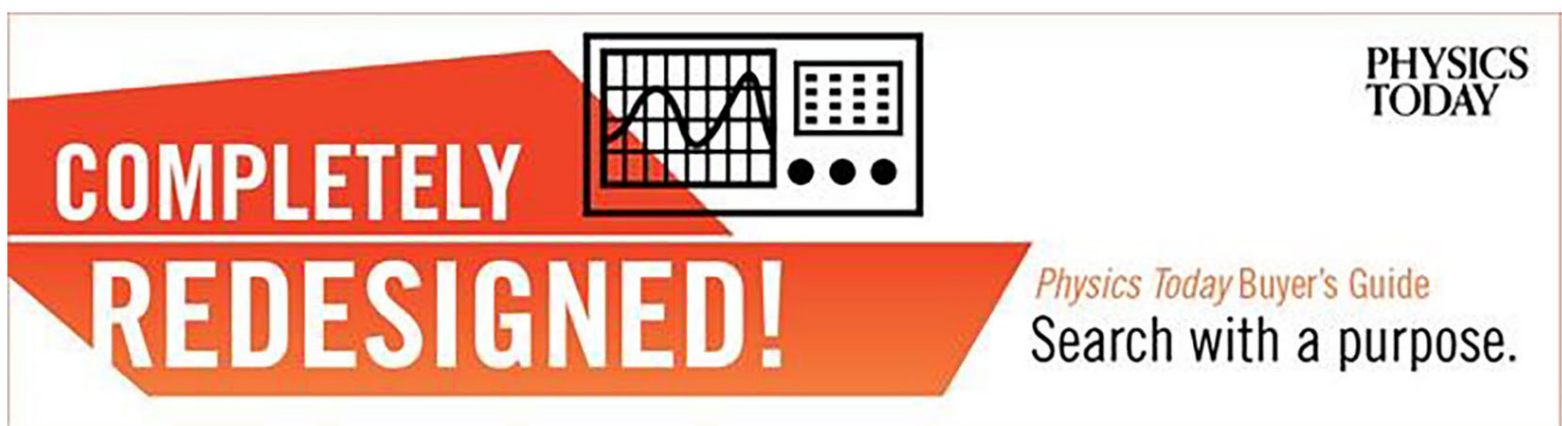




\title{
Molecular surface structure of tetracene mapped by the atomic force microscope
}

\author{
R. M. Overney, L. Howald, J. Frommer, E. Meyer, and H.-J. Güntherodt \\ Institut für Physik, Universität Basel, Klingelbergstrasse 82, CH-4056 Basel, Switzerland
}

(Received 17 December 1990; accepted 27 February 1991)

\begin{abstract}
The atomic force microscope has been used to record molecular structure on free-standing organic crystals. A crystal of tetracene has been imaged with molecular resolution which allows the assignment of lattice parameters to the surface layer. The intermolecular spacings on the surface of tetracene correspond remarkably closely with those in the bulk. It is even possible to distinguish between the two translationally inequivalent molecules of the unit cell. The mechanism for using force microscopy to distinguish between different molecular orientations is discussed.
\end{abstract}

\section{INTRODUCTION}

Tetracene is the four-ring analogue in the naphthaleneanthracene series of linear, fused benzene rings, Fig. $1 .^{1-3}$ Tetracene has been the subject of many studies of electronic and photonic processes of organic molecular crystals, in large part due to its high photosensitivity and ease in preparing evaporated layers. Many different analytical methods have been used to investigate tetracene's bulk structure, such as electron and $\mathrm{x}$-ray-diffraction, ${ }^{4}$ fluorescence resonance in a magnetic field, ${ }^{5}$ phonon emission detection, and optical spectroscopy. ${ }^{6}$ Calculations of atom-atom potentials and lattice dynamics ${ }^{7-9}$ have been performed to interpret or predict spectroscopic behavior. All of this work has focused on the bulk structure of tetracene. With the inception of the field of scanning force microscopies, ${ }^{10}$ the low concentration of surface molecules no longer eludes analysis.

The atomic force microscope (AFM) produces images of topography of conducting and nonconducting materials by scanning a sharp tip mounted on a cantilever-type spring over a sample surface. The spring deflects in response to its interactions with surface features. The spring deflection is monitored with electron tunneling, optical interference, deflection of a laser beam, or capacitance detection. Typical resolution is on the nanometer and angstrom scale. ${ }^{11-17}$

Since the first demonstration of atomic force microscopy in $1986,{ }^{10}$ many groups worldwide have used it to investigate ordered surfaces of crystalline materials, on inorganic $^{18.19}$ and organic ${ }^{20}$ systems. We present here the application of the AFM to a class of organic molecular crystals to provide information on surface molecular geometries previously unobtainable by other methods.

\section{EXPERIMENTAL}

All scans are performed with a commercially available microscope outfitted with a $1 \mu$ scanner and a beam deflection detection scheme. ${ }^{21}$ Cantilevers are V-shaped, $200 \mu \mathrm{m}$ long, and have integrated tips of $\mathrm{Si}_{3} \mathrm{~N}_{4}$ and spring constants of $0.12 \mathrm{~N} / \mathrm{m} .{ }^{22}$ The images are recorded in the ambient atmosphere, at room temperature, and on freshly cleaved samples. Scanning is performed on the $a b$-cleavage plane, the characteristic cleavage plane in this class of molecules. The AFM measurements reveal flat, defect-free surfaces over scanned areas of $1.0 \times 1.0 \mu \mathrm{m}^{2}$. Measurements made on tetracene crystals from different sources and with different scanning tips produce statistically similar results. Images are recorded from sublimed crystals obtained from both commercial $^{23}$ and local ${ }^{24}$ sources. The instrument is calibrated periodically with control samples of mica and graphite, yielding an uncertainty of $5 \%$. The images are recorded under conditions of insignificant drift, and are presented here as unfiltered, raw data. In performing these AFM measurements, the typical applied force is $15 \mathrm{nN}$. The application of higher forces has no apparent effect on the recorded images.

\section{RESULTS AND DISCUSSION}

It is well known from $x$-ray-diffraction studies ${ }^{3,4,25}$ that the tetracene crystal is triclinic with two molecules per unit cell (Fig. 1). These two translationally inequivalent mole-

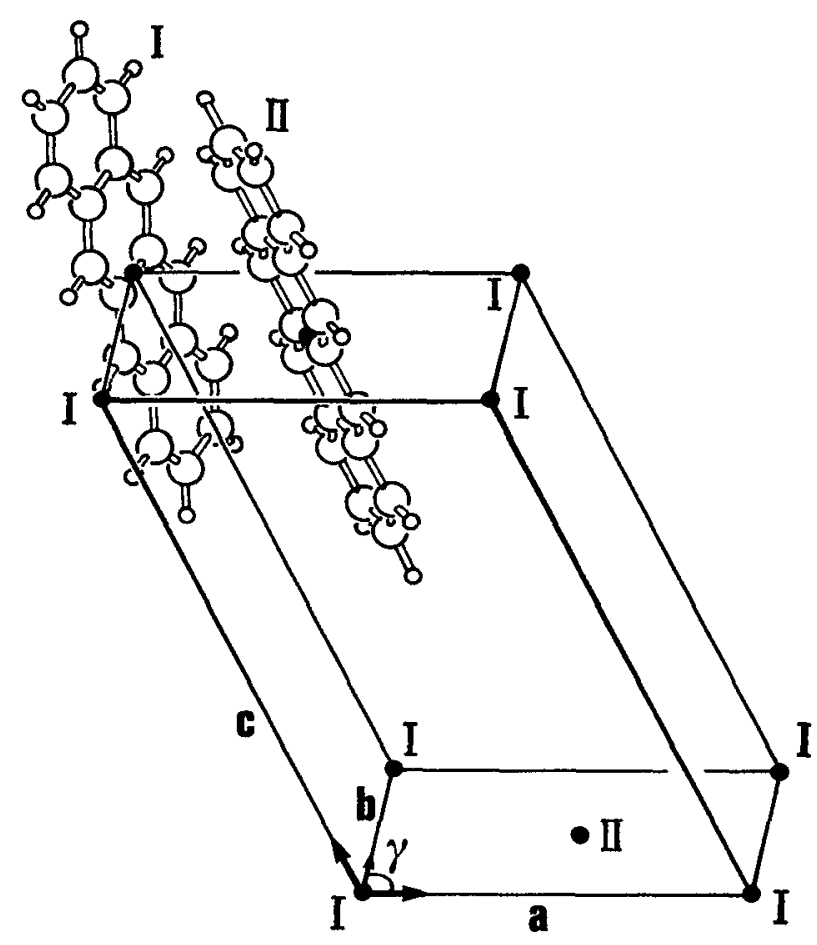

FIG. 1. The unit cell of crystalline tetracene in a perspective view. Representative molecules of type I and II are drawn in full to illustrate the orientations in the bulk. 
TABLE I. Crystallographic and AFM data of tetracene.

\begin{tabular}{lcc}
\hline \hline & $\begin{array}{c}\text { Tetracene lattice parameters } \\
\text { AFM }\end{array}$ & $\begin{array}{c}\text { Literature } \\
\text { (Refs. 3 and 25) } \\
\text { bulk }\end{array}$ \\
\hline$a(\AA)$ & & 7.915 \\
$b(\AA)$ & 8.0 & 6.065 \\
$c(\AA)$ & $\ldots .3$ & 13.445 \\
$\alpha\left(^{\circ}\right)$ & $\ldots$ & 101.10 \\
$\beta\left({ }^{\circ}\right)$ & $\ldots$ & 113.31 \\
$\gamma\left({ }^{\circ}\right)$ & 85.5 & 85.91 \\
\hline \hline
\end{tabular}

cules are designated I and II in Fig. 1. The crystallographic parameters are presented in Table I, along with the corresponding intermolecular spacings detected by AFM on the crystal surface. Figure 2 is an AFM image recorded over a $3.0 \times 3.0 \mathrm{~nm}^{2}$ area in which the $a$ and $b$ axes, and the angle $\gamma$ between them, have been measured and labeled. From the comparison of bulk and surface values (Table I), it can be seen that the arrangement of molecules in the $a b$ plane of the surface corresponds very closely to that of the bulk.

In Fig. 3(a), a $10 \times 10 \mathrm{~nm}^{2}$ image recorded at a slightly different scan angle across the sample, a superstructure of rows spaced $8.0 \AA$ can be discerned. To assign the features that make up the rows of Fig. 3(a), Fig. 3(b) has been constructed out of the bulk structural data. Figure $3(b)$ is the view looking down orthogonally on the $a b$ plane. This drawing, in which each molecule is represented as an ellipse, illustrates the nonparallel orientation of molecule types I and II relative to each other. It correlates well to the measured herringbone pattern of alternating type I and type II molecules in Fig. 3(a). The relative placements of these two molecular orientations within the unit cell, and the angles their short axes make with the $a b$ surface allow the identification of type I and type II molecules in our AFM images.

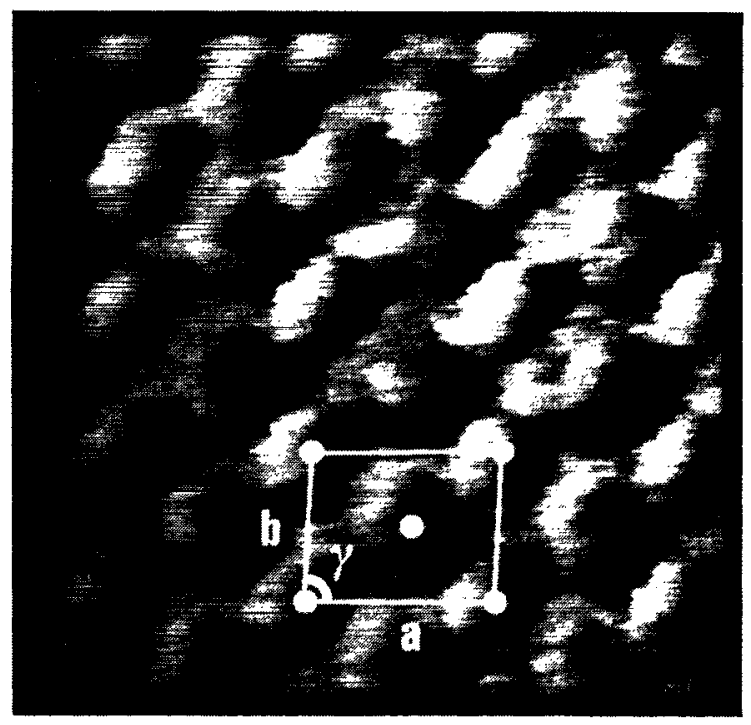

FIG. 2. AFM image of tetracene over an $3.0 \times 3.0 \mathrm{~nm}^{2}$ area. The scanned surface is the $a b$ plane of the crystal in which an arrangement of molecules corresponds to that of the bulk ( $\left.a=8.0 \AA, b=6.3 \AA, \gamma=85.5^{\circ}\right)$.
The short axes of the molecules are not perfectly parallel to the $a b$ plane, presenting a slightly tilted edge to the surface [see hatching in Fig. 3(b) ]. The combined effect of the different orientations of type I and type II molecules relative to each other, and their non-parallel orientations relative to the $a b$ plane, accounts for the shading (contrast) observed in the AFM image structure [Fig. 3(a)].

When the scan direction is rotated relative to the sample, the appearance of the superstructure can change. Different elastic responses to the AFM tip arising from the differ-

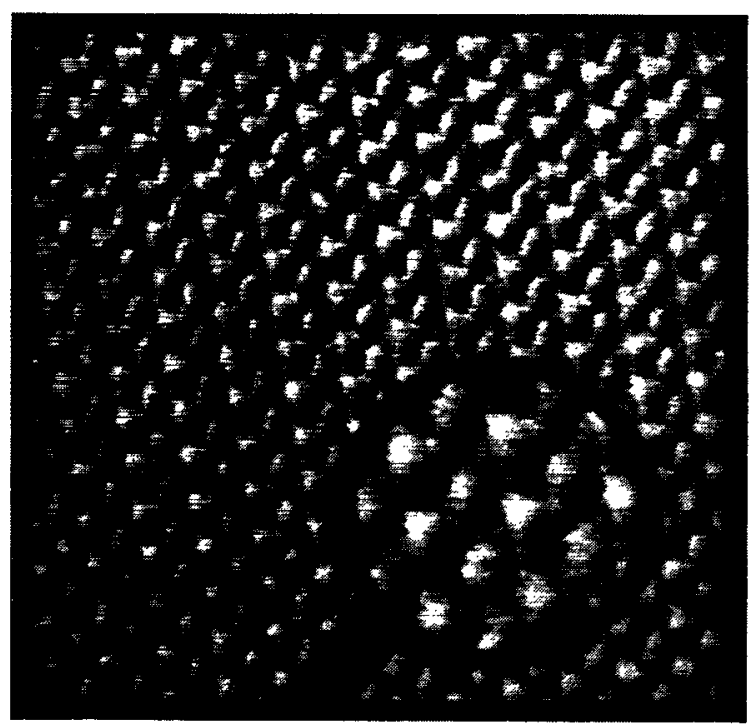

(a)

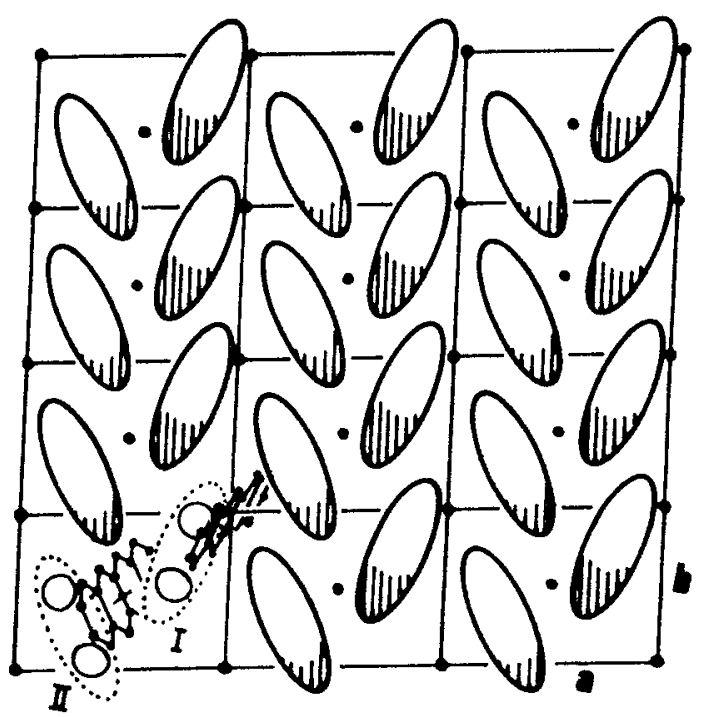

(b)

FIG. 3. (a) $10.0 \times 10.0 \mathrm{~nm}^{2}$ AFM image of the tetracene $a b$ plane. The inequivalent molecules, I and II, create a superstructure of rows spaced 8.0 $\AA$ apart. The magnified circle is of an area of about $20 \AA$ in diameter. (b) Schematic view of the bulk structure as viewed perpendicular to the $a b$ plane [same orientation as Fig. 3(a)]. Each ellipse represents the two physically topmost electron orbitals of one molecule with the lower of the two (by about $0.3 \AA$ ) being crosshatched. A herringbone pattern is visibly built up by the ellises. The dots represent the symmetry center of each molecule. One molecule of each type is outlined at the bottom left of the sketch. 
ent molecular orientations, I and II, would reinforce this effect. ${ }^{26}$ Obtaining these same results with a second tip preliminarily rules out an asymmetric tip effect. ${ }^{27}$

The close correlation between surface molecular structure, as detected by AFM, and interatomic distances, as determined in the bulk is worthy of note. On-going experiments in our laboratory on other analogues of fused aromatics reveal less correspondence between surface and bulk structures. These results require more extensive interpretration of molecular positions, and will be reported shortly.

\section{SUMMARY}

In our studies, the atomic force microscope, operated under ambient conditions, has provided information on the arrangement of molecules on the surface of tetracene crystals. We are able to differentiate between the two molecular orientations normal to the scanned plane and attribute this ability to the differential response of the tip to those two orientations. We conclude that the intermolecular spacing in the $a b$ plane of the bulk corresponds closely to that of the surface. Unlike other fused aromatic analogues that we have studied, the tetracene crystal structure appears to have remained intact on the crystal surface.

\section{ACKNOWLEDGMENTS}

We wish to thank Dominique Brodbeck, Martin Haber, Walter Littke, Gregor Overney, Martin Pope, and Iris Zschokke. This work was supported by the Swiss National Science Foundation and the Kommission zur Förderung der wissenschaftlichen Forschung.
'J. M. Robertson, V. C. Sinclair, and J. Trotter, Acta Cryst. 14, 697 (1961), ${ }^{2}$ S. Nes̃purek and E. A. Silinsh, Phys. Stat. Solidi (a) 34, 747 (1976).

${ }^{3}$ R. B. Campbell and J. M. Robertson, Acta Cryst. 15, 289 (1962).

${ }^{4}$ Y. Maruyama and N. Iwasaki, Chem. Phys. Lett. 24, 26 (1974).

${ }^{5}$ R. Jankowiak, H. Bässler, and A. Kutoglu, J. Appl. Phys. 89, 5705 (1985)

${ }^{6}$ W. Dietsche, Th. Rapp, and H. C. Basso, J. Appl. Phys. 59, 1431 (1986).

${ }^{7}$ A. I. Kitaigorodskii, Chem. Soc. Ref. 7, 133 (1978).

${ }^{8} \mathrm{D}$. E. Williams, Topics in Current Physics (Springer-Verlag, West Berlin 1981), Vol. 26, p. 9.

${ }^{9}$ G. Filippini and C. M. Gramaccioli, Chem. Phys. Lett. 104, 50 (1984).

${ }^{10} \mathrm{G}$. Binnig, C. F. Quate, and Ch. Gerber, Phys. Rev. Lett. 56, 930 (1986).

"G. Binnig, Ch. Gerber, E. Stoll, T. R. Albrecht, and C. F. Quate, Europhys. Lett. 3, 1281 (1987).

${ }^{12}$ E. Meyer, H. Heinzelmann, P. Grütter, Th. Jung, Th. Weisskopf, H. R. Hidber, R. Lapka, H. Rudin, and H -J. Güntherodt, J. Microsc. 152, 269 (1988).

${ }^{13}$ T. R. Albrecht and C. F. Quate, J. Appl. Phys. 62, 2599 (1987).

${ }^{14}$ M. Egger, F. Ohnesorge, A. L. Weisenhorn, S. P. Heyn, B. Drake, C. B. Prater, S. A. C. Gould, P. K. Hansma, and D. E. Gaub, J. Struct. Bio. 103, 89 (1990).

${ }^{15}$ A. L. Weisenhorn, H. E. Gaub, H. G. Hansma, S. L. Sinsheimer, G. L. Keldermann, and P. K. Hansma, Scan. Microscopy 4, 511 (1990).

${ }^{16}$ E. Meyer, L. Howald, R. M. Overney, H. Heinzelmann, J. Frommer, and H.-J. Güntherodt, Nature 349, 398 (1991).

${ }^{17} \mathrm{D}$. Rugar and P. Hansma, Phys. Today 43, 23 (1990).

${ }^{18} \mathrm{G}$. Meyer and N. Amer, Appl. Phys. Lett. 56, 21 (1990).

${ }^{19}$ H. Heinzelmann, E. Meyer, H. Rudin, H.-J. Güntherodt, NATO Meeting Basic Concepts and Appl. of Scanning Tunneling Microscopie (STM) and Related Techniques, April 17-29, 1989.

${ }^{20}$ S. Gould, O. Marti, B. Drake, L. Hellemans, C. E. Bracker, P. K. Hansma, N. L. Keder, M. M. Eddy, and G. D. Stucky, Nature 332, 332 (1988).

${ }^{21}$ Nanoscope II AFM, Digital Instruments Inc., Santa Barbara, CA.

${ }^{22}$ Park Scientific Instruments, Mountain View, CA.

${ }^{23}$ Aldrich Chemical Company Inc., Milwaukee, Wisconsin.

${ }^{24}$ I. Zschokke, Institut für Physik der Universität Basel, Basel, Switzerland.

${ }^{25}$ C. E. Truscott and B. S. Ault, J. Phys. Chem. 89, 1741 (1984).

${ }^{26}$ U. Sondermann, A. Kutoglu, and H. Bässler, J. Phys. Chem. 89, 1735 (1985).

${ }^{27}$ S. A. C. Gould, K. Burke, and P. K. Hansma, Phys. Rev. B 40, 5363 (1989). 